\title{
New Single-Component Resists Based on Functional Polynorborneneimides by Chemical Amplification for Deep UV Lithography
}

\author{
Chan-Woo Lee, Jung-Han Shin, Jong-Hee Kang, Jong-Man Kim, Dong-Keun Han, \\ and Kwang-Duk Ahn*
}

\author{
Functional Polymer Laboratory, Korea Institute of Science and Technology, \\ 39-1, Hawolkok-dong, Sungbuk-ku, Seoul 136-791, Korea
}

\begin{abstract}
Keywords: single-component resists, norborneneimide polymers, polymeric photoacid generators, deep UV resists
\end{abstract}

\section{Introduction}

We have previously reported polymeric photoacid generators (PAG) of $N$-(tosyloxy)maleimide (TsOMI), $N$-(trifluoromethanesulfonyloxy)maleimide (TfOMI), and $N-(10-$ camphorsulfonyloxy)maleimide (CSOMI) which generate the corresponding sulfonic acids, $p$ toluenesulfonic acid ( $\mathrm{TsOH}$ ), trifluoromethanesulfonic acid ( $\mathrm{TfOH}$ ), and camphorsulfonic acid (CSA), respectively, by deep UV (DUV) irradiation.[1-3] These polymeric PAGs were utilized for designing single-component resist systems. The single-component resist system is constructed by the polymers consisting of two major functional components, which are the photoacid-generating unit and the acid-labile unit, if need, one more unit for improving resist properties. Recently, we have reported two kinds of polymeric CSA generators, $\mathrm{P}[\mathrm{CSOMI} / \mathrm{t}-$ BOCMI/VP] and P[CSOMI/t-BOCVC], which are the terpolymers of CSOMI, $N$-(tertbutyloxycarbonyl)maleimide (t-BOCMI), 1-vinyl2-pyrrolidinone (VP), and t-BOC-protected vinylcaprolactam (t-BOCVC). $[4,5] \quad$ The terpolymers possess the capability of singlecomponent resist system based on the chemical amplification concept without any added PAG. This type of resist system should be free of the compatibility problem arising by addition of a PAG due to its low solubility in the resist media.[6] The copolymers of CSOMI offer promising resist properties in practical points of view both the polymeric PAG and the bulky generated acid CSA.[7]

Current research efforts for resist materials in
ArF lithography have focused on the alicyclic polymers based on norbornene monomers because such alicyclic main chains provide effective plasma etch resistance as well as low absorbance at 193 $\mathrm{nm}$.88-10] To apply the single-component resist system in the DUV region, we have extended the design concept to alicyclic polymers containing photoacid-generating norbornene-type monomers. This novel single-component resist system is primarily based on terpolymers of $\mathrm{N}-(10-$ camphorsulfonyloxy)norboneneimide (CSNBI) and $N$-(tosyloxy)norborneneimide (TsNBI). The designed polymers were obtained by electron donor/acceptor (EDA) radical polymerization utilizing CSNBI, TsNBI, and $t$-butyl bicyclo[2.2.1] hept-5-ene-2-carboxylate (t-BOCNB) as an electron-donor monomer and maleic anhydride or maleimides as an electron-acceptor monomer.[9-12]

The novel resist polymers based on two kinds of norborneneimides, CSNBI and TsNBI, were synthesized and the preliminary evaluation as the single-component resist system will be discussed.

\section{Experimental}

\subsection{Preparation of CSNBI and TsNBI}

CSNBI and TsNBI were readily prepared by reactions of endo- $N$-hydroxy-5-norbornene-2,3dicarboximide (HONBI) with 10-camphorsulfonyl chloride and $p$-toluenesulfonyl chloride, respectively, in the presence of triethylamine. The reaction mixture was poured into large excess of ether to precipitate triethylamine salt followed by filtration. Then the mixture was dried under vacuum and poured into a mixture of methanol/ $\mathrm{H}_{2} \mathrm{O}$ 
to precipitate the product. The yields in the reaction were $85 \%$ for CSNBI and $90 \%$ for TsNBI, respectively.

\subsection{Preparation of $t-B O C N B$}

The $t-B O C$ protected norbornene ( $t-B O C N B)$ was prepared by a Diels-Alder reaction between the commercial dicyclopentadiene and $t$-butyl acrylate at $180^{\circ} \mathrm{C}$ in a pressure reactor.[12] The reaction products were purified by fractional distillation or silica gel columns using hexane as an eluent.

\subsection{Polymerization}

Radical terpolymerizations were carried out at $80^{\circ} \mathrm{C}$ in dioxane for $5 \mathrm{~h}$ using $2 \mathrm{~mol} \%$ of benzoyl peroxide (BPO) as an initiator with respect to the combined monomers. Monomers (CSNBI or TsNBI/t-BOCNB/MAh or t-BOCMI) were fed in the molar ratio of 1:1:2 in ampoules and sealed under reduced pressure after freeze-thaw cycles and then polymerized under argon atmosphere. The polymers were obtained by precipitation into methanol and dried in vacuo. One of the terpolymers, $\mathrm{P}[\mathrm{CSNBI} / \mathrm{t}-\mathrm{BOCNB} / \mathrm{MAh}]$, was obtained in a yield of $40 \%$ with a molecular weight of 6000 by GPC. The other terpolymer, $\mathrm{P}[\mathrm{TsNBI} / \mathrm{t}-\mathrm{BOCNB} / \mathrm{MAh}]$, was obtained in a yield of $50 \%$ with a molecular weight of 7000 .

\subsection{Measurements}

Chemical structures were determined by infrared spectroscopy (Mattson Genesis Series FT-IR) and ${ }^{1} \mathrm{H}$ and ${ }^{13} \mathrm{C}$ NMR spectroscopy (200 $\mathrm{MHz}$ Varian Gemini). Molecular weights of the polymers were measured by GPC with a Waters Model 150-C ALG system calibrated with polystyrene standards using THF as a solvent. The absorbance of the films was recorded on a Shimadzu UV-240 spectrophotometer using a quartz plate.

\subsection{Resist evaluation}

A $15 \%(w / w)$ solution of the terpolymer in cyclohexanone was prepared and filtered with a membrane filter of $0.2-\mu \mathrm{m}$ pore size. Hydroquinone (HQ), $5 \mathrm{wt} \%$ with respect to the polymer, was used as an additive. The solutions were spin-coated with a Headway Research spin coater and baked on a hot plate at $100{ }^{\circ} \mathrm{C}$ for $1 \mathrm{~min}$ to make 0.5 to $0.7-\mu \mathrm{m}$ thick films. The thickness of the film was measured with a profilometer Model P-10 (Tencor Instrument). The developer was a commercial
$2.38 \%$ tetramethylammonium hydroxide (TMAH) solution. DUV exposure was performed on UV illuminators of Ushio Inc. equipped with a $500 \mathrm{~W}$ $\mathrm{Hg}$-Xe lamp using a narrow band-pass filter for 250 nm.

\section{Results and Discussion}

\subsection{Monomer Synthesis and Polymerization}

Two novel photoacid-generating norbornene monomers, CSNBI (mp, $174-175^{\circ} \mathrm{C}$ ) and TsNBI $\left(\mathrm{mp}, 149-150^{\circ} \mathrm{C}\right)$ were prepared in high yields by reacting HONBI with 10-camphorsulfonyl chloride and $p$-toluenesulfonyl chloride, respectively, as described in Fig. 1.

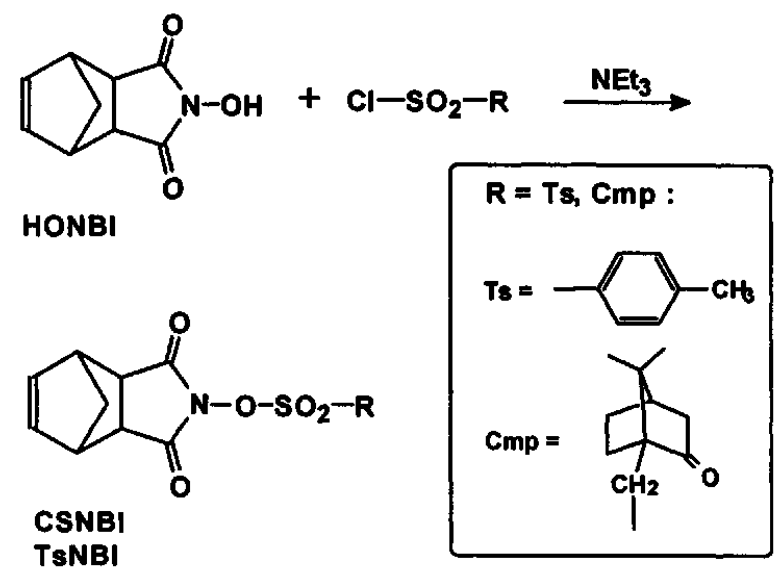

Fig. 1. Synthesis of photoacid-generating monomers, CSNBI and TsNBI.

The chemical structures of CSNBI and TsNBI were identified by NMR and IR spectra. A $t$ butyl bicyclo[2.2.1]hept-5-ene-2-carboxylate (tBOCNB as t-BOC-norbornene) was prepared by a Diels-Alder reaction from commercially available dicyclopentadiene (DCP) and $t$-butyl acrylate (t$\mathrm{BA}$ ). These norbornene derivatives such as CSNBI, TsNBI, and t-BOCNB are hardly homopolymerizable while they could copolymerize with strongly electron-accepting monomers such as maleic anhydride (MAh) and various maleimide derivatives by virtue of EDA radical polymerization.[8-12] Terpolymers P[CSNBI/tBOCNB/MAh] and P[TsNBI/t-BOCNB/MAh] were successfully obtained by polymerizations of CSNBI or TsNBI and t-BOCNB with MAh (molar ratio of 1:1:2) in the presence of the BPO initiator as shown in Fig. 2. Radical terpolymerizations of 
CSNBI (or TsNBI), t-BOCNB and MAh with a feed ratio of $1: 1: 2$ gave $P[C S N B I / t$ BOCNB/MAh] and P[TsNBI/t-BOCNB/MAh] (composition of $\mathrm{x}: \mathrm{x}: \mathrm{y}$ ) in 40 to $50 \%$ yields with molecular weights in the range of 6000 to 10000 by GPC.

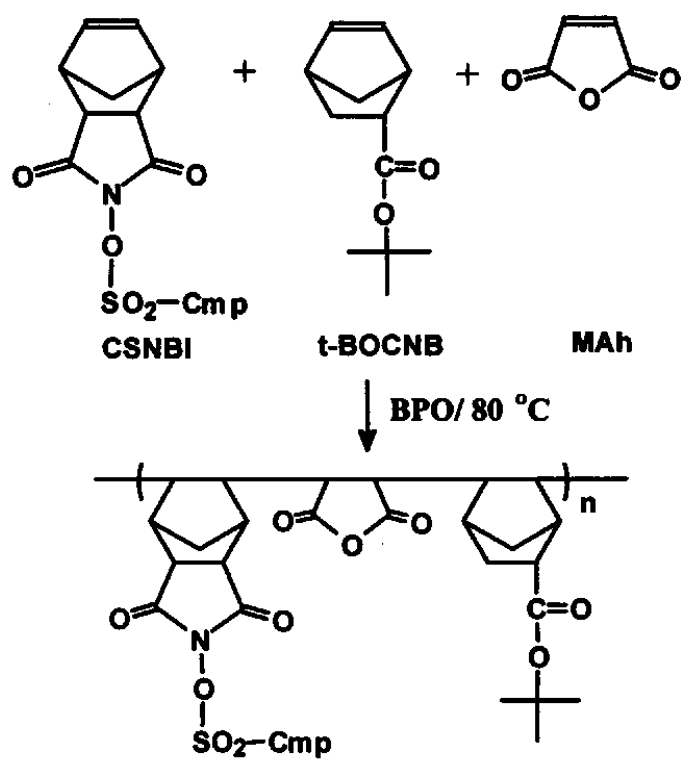

P[CSNBI/t-BOCNB/MAh] (1:1:2)

Fig. 2. Terpolymers of CSNBI, $t-B O C N B$ and MAh by EDA radical terpolymerization.

\subsection{Thermal and Acidolytic Deprotection}

The terpolymers, P[CSNBI/t-BOCNB/MAh] and $\mathrm{P}[\mathrm{TsNBI} / \mathrm{t}-\mathrm{BOCNB} / \mathrm{MAh}]$, revealed endothermic events at $210^{\circ} \mathrm{C}$ and $215^{\circ} \mathrm{C}$, respectively, corresponding to the removal of $t-B u$ groups leaving carboxylic acid groups in the norbornyl moieties by DSC analysis. This thermal deprotection behavior in the pendent $t-$ BOC groups was also confirmed by analyzing FTIR spectra and TGA thermograms. Upon exposure to $250-\mathrm{nm}$ DUV with $100 \mathrm{~mJ} / \mathrm{cm}^{2}$, $\mathrm{P}[\mathrm{CSNB} \mathrm{l} / \mathrm{t}-\mathrm{BOCNB} / \mathrm{MAh}] \quad(1: 1: 2) \quad$ and $\mathrm{P}$ TsNBI/t-BOCNB/MAh] (1:1:2) showed endothermic events at 160 and $150^{\circ} \mathrm{C}$, respectively, as shown in Fig. 3. The lowered deprotection temperature of $t-B O C$ groups in $\mathrm{P}[\mathrm{CSNBI} / \mathrm{t}-\mathrm{BOCNB} / \mathrm{MAh}]$ by DUV irradiation

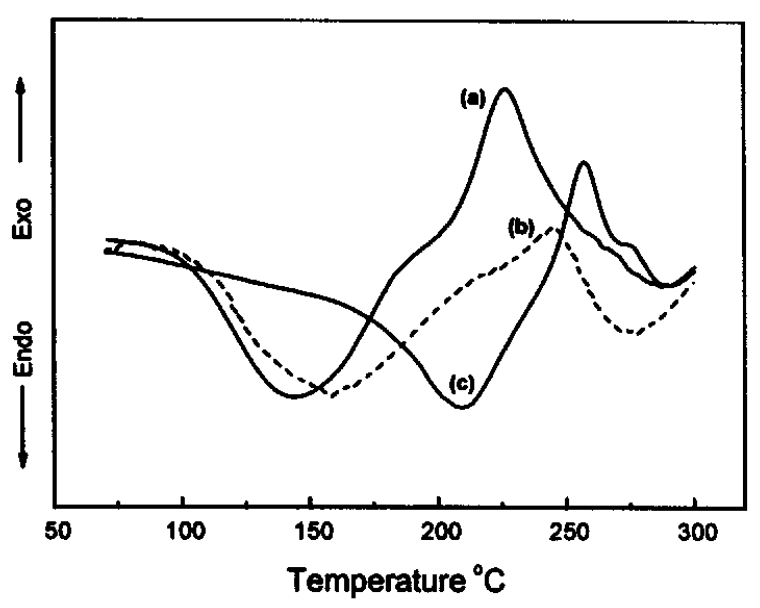

Fig. 3. DSC thermograms of $\mathrm{P}[\mathrm{CSNBI} / \mathrm{t}-\mathrm{BOCNB} /$ MAh] by exposure to DUV with $100 \mathrm{~mJ} / \mathrm{cm}^{2}$ : endothermic peaks appeared at (a) $140^{\circ} \mathrm{C}$ with 5 wt $\% \mathrm{HQ}$, (b) $160^{\circ} \mathrm{C}$ without $\mathrm{HQ}$, and (c) $210^{\circ} \mathrm{C}$ without exposure.

is indicative of the self-photoacidolytic deprotection and applicability as single-component resists.

Thermal and photoacidolytic deprotection of tBOC groups in P[CSNBI/t-BOCNB/MAh] (1:1:2) and $\mathrm{P}$ [CSNBI $/ \mathrm{t}-\mathrm{BOCNB} / \mathrm{MAh}](1: 1: 2)$ by TGA resulted in nearly the same mass loss of $9 \mathrm{wt} \%$, which corresponds to the theoretically calculated weight loss due to the evolution of isobutylene from the terpolymers. When the films of P[CSNBI/tBOCNB/MAh] containing $5 w t \%$ hydroquinone (HQ) as an additive were irradiated with DUV, the deprotection temperatures lowered than that measured without using HQ. Then the deprotected polymer exhibited a stable plateau until the onset decomposition of CSNBI units at about $260^{\circ} \mathrm{C}$ in TGA thermograms. At about $250^{\circ} \mathrm{C}$, most copolymers of sulfonyloxymaleimides revealed onset decomposition of those units from the copolymer chains.[1-3] This implies complete acidolytic deprotection of the $t-B O C$ groups by the photogenerated CSA in the same polymer chains as shown in Fig. 4.

In Fig. 4, at the first step, P[CSNBI/tBOCNB/MAh] generates camphorsulfonic acid photochemically as much as $\mathrm{x}$ mole fraction by DUV exposure. In the second step, the small amounts of the generated sulfonic acid in the film catalyze the acidolytic deprotection of $\mathrm{t}-\mathrm{Bu}$ in $\mathrm{t}$ BOC groups at temperatures lower than the thermal deprotection of the terpolymer itself without 


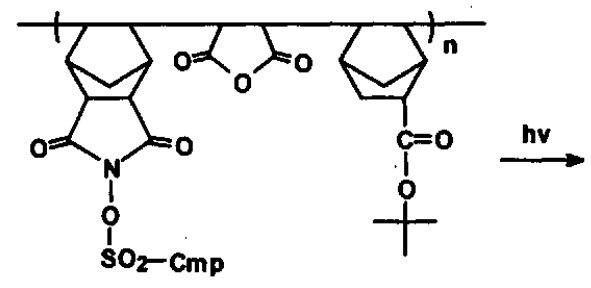

P[CSNBI/T-BOCNB/MAh]
Photoacld Generation

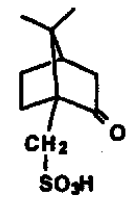

CSA
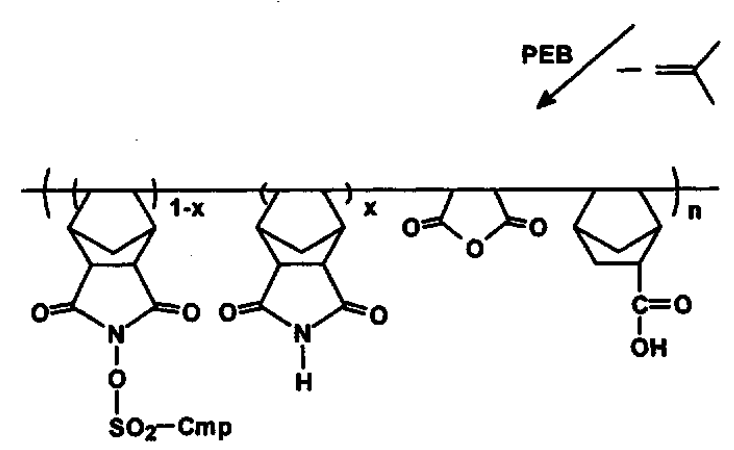

Fig. 4. Acidolytic deprotection of $t-B u$ groups by the photo-generated CSA in P[CSNBI/t-BOCNB/MAh].

exposure. Thus, the acid-labile groups were readily deprotected to produce highly polar functionalities.

UV absorbance of P[CSNBI/t-BOCNB/MAh] and $\mathrm{P}[\mathrm{TsNBI} / \mathrm{t}-\mathrm{BOCNB} / \mathrm{MAh}]$ was measured to be $0.2 / \mu \mathrm{m}$ and $0.35 / \mu \mathrm{m}$ at $250 \mathrm{~nm}$ wavelength while it was about 2 times higher values in 193 $\mathrm{nm}$ region. The $\mathrm{t}-\mathrm{BOC}$ protected terpolymers were insoluble in the commercial TMAH solution but became quite soluble when deprotected to carboxy groups. Thus, the basic resist properties of the terpolymers imply that the terpolymers possess the capability of applications for $\mathrm{KrF}$ and ArF lithography.

\section{Acknowledgment}

The authors are grateful to the Korea Ministry of Science and Technology for the financial support on the research project of advanced resist materials performed in KIST.

\section{References}

1. K.-D. Ahn, C.-M. Chung, and D.-I. Koo, Chem. Mater., 6 (1994) 1452.

2. (a) C.-M. Chung, D.-I. Koo, and K.-D. Ahn, $J$. Photopolym. Sci. Technol., 7 (1994) 473. (b) C.-M. Chung and K.-D. Ahn, J. Photopolym. Sci. Technol., 9 (1996) 553.

3. K.-D. Ahn, J.-S. Koo, and C.-M. Chung, $J$. Polym. Sci., Polym. Chem., 34 (1996) 183.

4. S.-T. Kim, J.-B. Kim, M.-H. Jung, and K.-D. Ahn, Polym. Bull., 39 (1997) 423.

5. S.-T. Kim, J.-B. Kim, J.-M. Kim, C.-M. Chung, and K.-D. Ahn, J. Photopolym. Sci. Technol., 10 (1997) 489.

6. J. W. Thackeray et al., J. Photopolym. Sci. Technol., 7 (1994) 619.

7. J. E. Hanson, E. Reichmans, F. M. Houlihan, and T. X. Neenan, Chem. Mater., 4 (1992) 837.

8. F. M. Houlihan, T. I. Wallow, O. Nalamasu, and E. Reichmanis, Macromolecules, 30 (1997) 6517.

9. U. Okoroanganwu, T. Shimokawa, J. Byers, D. Medeiros, C. G. Willson, Q. J. Niu, J. M. J. Frechet, and R. Allen, Proc. SPIE., 3049 (1997) 92.

10. Q. J. Niu and J. M. J. Fréchet, Angew. Chem. Int. Ed., 37 (1998) 667.

11. H. K. Hall, Jr. and A. B. Padias, Acc. Chem. Res., 30 (1997) 322.

12. K.-D. Ahn et al., J. Photopolym. Sci. Technol., (1998) to be published. 